\title{
INTERPRETASI AYAT IDDAH BAGI WANITA MENOPAUSE, AMENOREA, DAN HAMIL DENGAN PENDEKATAN MEDIS
}

\author{
Nur Lailatul Musyafa'ah \\ Universitas Islam Negeri Sunan Ampel Surabaya | II. A. Yani I I 7 Surabaya \\ nurlailashafaa@gmail.com
}

\begin{abstract}
This article discusses the verse of the Quran concerning iddah (waiting period after divorce or death of husband). The concerned verse is QS. 65:4. It stipulates iddah for menopause women, amenorrhea women, and pregnant women. Muslim jurists agree that waiting period for menopause and amenorrhea women is three lunar months, whereas pregnant women must wait until labor. Medical examination shows several advantages for waiting period. Firstly, the word "in irtabtum" (when you have doubt) in the verse for menopause women, that women before menopause tend to get their menstrual period irregularly which in medical perspective a menopause women are those who have not get their menstrual period in a full year. Secondly, the attribute to women who not yet get menstruation and not yet pregnant, because there are two types of amenorrhea; primary and secondary. Primary amenorrhea for those who never get menstruation whereas secondary amenorrhea is caused by pregnancy or other causes. Thirdly, the attribute in the verse of iddah for pregnant women with "an yadha'na hamlahunna" not with "an yalidna" means that pregnancy take place when ovum was fertilized by sperm. Thus, when there is no pregnancy, either because of miscarriage or labor, the iddah concludes.
\end{abstract}

Key words: iddah, Quranic interpretation, medical knowledge

Abstrak: Ayat iddah yang dimaksud dalam artikel ini adalah QS. 65:4, yang menjelaskan tentang iddah bagi wanita menopause, wanita yang belum haid (amenorea) dan wanita hamil. Ulama sepakat bahwa iddah wanita menopause dan wanita yang belum haid adalah tiga bulan, dan iddah wanita hamil adalah melahirkan. Dengan pendekatan medis diketahui beberapa hikmah, di antaranya: Pertama, penyebutan "in irtabtum" (jika kalian ragu) bagi iddah wanita menopause, bahwa sebelum menopause biasanya wanita mengalami haid yang tidak teratur, dan dalam perspektif medis, seorang wanita dikatakan menopause

\footnotetext{
AL-DAULAH: JURNAL HUKUM DAN PERUNDANGAN ISLAM VOLUME 8, NOMOR 1, APRIL 2018$$
\text { p-ISSN 2089-0109; e-ISSN 2503-0922 }
$$

Homepage: http://jurnalfsh.uinsby.ac.id/index.php/aldaulah

Email: judulsj@gmail.com
} 
apabila sudah tidak haid selama satu tahun. Kedua, penyebutan wanita belum haid sebelum hamil, karena secara medis, wanita belum haid (amenorea) ada dua; amenorea primer dikarenakan belum haid sama sekali dan amenorea sekunder dikarenakan kehamilan atau sebab lain. Ketiga, penyebutan iddah wanita hamil dengan kalimat "an yadha'na hamlahunna" bukan dengan kalimat "an yalidna", bahwa kehamilan telah terjadi ketika ovum bertemu sperma, maka ketika kehamilan itu tiada, baik karena keguguran atau melahirkan maka masa iddahnya berakhir.

Kata kunci: Interpretasi, ayat, iddah, medis.

\section{Pendahuluan}

Dalam fikih, hukum yang berkaitan dengan masalah kewanitaan dibahas dalam kajian fikih wanita yang disebut "figh almar'ah" atau "figh al-nisâ"'. ${ }^{1}$ Di antara kajian yang dibahas dalam fikih wanita adalah masalah iddah. Iddah adalah kewajiban yang harus dijalani seorang wanita setelah terjadinya perceraian. Kewajiban ini merupakan doktrin dalam Islam yang bersumber langsung dari al-Qur'an dan hadis, dan bahkan menjadi konsensus para pakar hukum Islam. ${ }^{2}$

Pemberlakuan iddah sudah ada jauh sebelum Islam datang, meskipun praktiknya tentu jauh berbeda. Tatkala Islam datang, tradisi ini masih tetap dipertahankan dengan berbagai perbaikan dengan tujuan untuk kemaslahatan. Penerapan pada zaman Nabi saw tidak terlepas dari pengaruh sosio-kultural masyarakat Arab pada waktu itu. Kondisi sosio-kultural pada saat diturunkannya ketentuan dan aturan tentang iddah, juga tidak terlepas dari latar belakang kehidupan bangsa Arab pra-Islam dengan budaya patriarkhi, yang menganggap kedudukan perempuan dipandang lebih rendah dibandingkan dengan laki-laki. Pemberlakuan iddah merupakan ketentuan hukum yang harus diimani dan dilaksanakan oleh para mukallaf tanpa perlu mempertanyakan apalagi menggugatnya, dan merupakan perwujudan ketaatan

\footnotetext{
I Nur Lailatul Musyafa'ah, "Rekonstruksi Fiqh Pendarahan Pervaginam dengan Pendekatan Medis", Islamica, Volume 8, Nomor I, (September 2013), 168.

2 Abdul Helim, "Membaca Kembali Doktrin Iddah dalam Perspektif Ushûl al-Fiqh", Karsa, Volume 20, Nomor 2, (Desember Tahun 2012), 279.
} 
hamba kepada Allah swt. Yang perlu untuk ditafsirkan kembali adalah tujuan iddah yang terkandung dalam pemberlakuan iddah bagi perempuan, baik karena cerai hidup maupun cerai mati. Kalau tujuan iddah hanya untuk mengetahui kebersihan rahim, seyogyanya dengan satu kali haid sudah menunjukkan perempuan itu tidak hamil. Mengapa perempuan yang dicerai harus menunggu tiga kali suci, dan tiga bulan bagi yang belum haid atau menopause, dan empat bulan sepuluh hari bagi perempuan yang ditinggal mati suaminya.

Perkembangan ilmu pengetahuan dan teknologi modern tidak dapat mengubah ketentuan panjang-pendeknya iddah, terutama dalam kasus-kasus yang sudah jelas dikemukakan al-Qur'an dan hadis. Sekalipun diyakini dengan ilmu pengetahuan dan teknologi bahwa rahim istri bersih dan di antara mereka (suami-istri) tidak mungkin rujuk kembali, namun tidak dibenarkan bagi wanita melanggar ketentuan iddah yang sudah ditetapkan. ${ }^{3}$

Bagi wanita yang dicerai, tidaklah boleh langsung menikah, melainkan memiliki masa menunggu yang disebut iddah. Iddah dimaksudkan untuk mengetahui wanita tersebut hamil atau tidak, dan juga menentukan kelanjutan hubungan mereka. ${ }^{4}$ Iddah memang merupakan suatu persoalan yang sangat krusial di kalangan pemikir-pemikir zaman dahulu maupun sekarang. Selain dinilai sebagai bias gender, sehingga banyak mengundang para cendekiawan mengkaji esensi dari iddah ini. Para ulama, terutama ulama fikih juga masih memperdebatkan masalah iddah karena adanya perkembangan permasalahan fikih. Hal ini tak luput dari adanya kemajuan ilmu pengetahuan dan teknologi. ${ }^{5}$ Sekarang, permasalahan yang ada pada masyarakat semakin komplek seiring berkembangnya ilmu pengetahuan dan teknologi yang semakin

\footnotetext{
${ }^{3}$ Nurnazli, "Relevansi Penerapan Iddah di Era Teknologi Modern", ljtimaiyya: Jurnal Pengembangan Masyarakat Islam, Volume 10, Nomor I, (2017), 122-123.

${ }^{4}$ Ahmad Muslimin, "Iddah dan Ihdad Wanita Modern", Mahkamah, Volume 2, Nomor 2, (Desember 2017), 219.

${ }^{5}$ Ulin Nuha, Analisis Pendapat Mazhab Hanafi tentang Iddah bagi Wanita yang belum Haid, -Skripsi--, (Semarang: Uinversitas Islam Negeri, 20 I6), 2.
} 
pesat. Sehingga tuntutan terhadap upaya ijtihad dalam upaya mencari solusi dari segala permasalahan tanpa meninggalkan ajaran-ajaranNya. ${ }^{6}$

Dengan mengkaji lebih dalam tentang iddah diharapkan menemukan ajaran yang sejati, original dan memadai dengan situasi yang dihadapi saat ini. Setidaknya, ada dua hal yang menjadi acuan sekaligus sebagai bahan pertimbangan dalam memahami makna 'iddah. Pertama, saat ini, perkembangan ilmu pengetahuan dan teknologi, khususnya dalam bidang kedokteran telah memungkinkan untuk mengetahui kehamilan dalam waktu singkat dengan hasil akurat. Kedua, seiring dengan semakin majunya cara berpikir manusia, maka semakin menggema dan dahsyatnya suarasuara yang menggugat berbagai ketidakadilan gender di masyarakat yang dialami oleh laki-laki atau perempuan, hanya saja dibandingkan laki-laki, perempuan lebih banyak mengalami ketidakadilan, terutama dalam pemenuhan hak asasi mereka. ${ }^{7}$

Islam datang untuk mengatur secara adil praktik iddah, dengan penetapan masa iddah yang telah dijalankan sejak masa Rasulullah. Namun ketika zaman telah berkembang yang berakibat pada perbedaan kondisi sosial masyarakat antara masa doktrin klasik, dengan masa sekarang, di samping kecanggihan teknologi telah membuka cakrawala baru, mendorong adanya koreksi serta perumusan konsepsi fikih yang aplikatif, adaptif, dan humanis untuk masa sekarang. ${ }^{8}$ Teknologi dalam bidang medis juga berpengaruh pada pengetahuan tentang konsep menopause, amenorea dan kehamilan. Ketiga hal tersebut berkaitan dengan iddah sebagaimana dijelaskan dalam al-Qur' an QS. 65:4.

Berdasarkan latar belakang tersebut, penulis tertarik untuk membahas tentang interpretasi ayat iddah bagi wanita menopause, amenorea dan wanita hamil dengan pendekatan medis.

\footnotetext{
6 Ahmad Muslimin, "Iddah dan Ihdad Wanita Modern", Mahkamah, Volume 2, Nomor 2, (Desember 2017), 219.

7 Indar, "Iddah dalam Keadilan Gender", Yinyang, Volume 5, Nomor I, (Januari-Juni 20 I0), I I 3.

${ }^{8}$ Edi Susilo, "Iddah dan Ihdad Wanita Karir", al-Hukama: The Indonesian Journal of Islamic Family Law, Volume 06, Nomor 02, (Desember 2016), 276.
} 


\section{Menopause dalam Perspektif Medis}

Menopause ialah haid terakhir, atau saat terjadinya haid terakhir. Diagnosis menopause dibuat setelah terdapat amenorea sekurang-kurangnya satu tahun. Berhentinya haid dapat didahului oleh siklus haid yang lebih panjang, dengan perdarahan yang berkurang. ${ }^{9}$ Menopause adalah periode menstruasi spontan yang terakhir pada seorang wanita dan merupakan diagnosis yang ditegakkan secara retrospektif setelah amenorea selama 12 bulan. ${ }^{10}$

Menopause adalah berhentinya secara fisiologis siklus menstruasi yang berkaitan dengan tingkat lanjut usia perempuan. Seorang wanita yang mengalami menopause alamiah sama sekali tidak dapat mengetahui apakah saat menstruasi tertentu benarbenar merupakan menstruasinya yang terakhir sampai satu tahun berlalu. Menopause kadang-kadang disebut sebagai perubahan kehidupan. ${ }^{11}$

Fase transisi fluktuasi fungsi ovarium yang terjadi di sekitar waktu perdarahan menstruasi terakhir dari seorang wanita dikenal sebagai perimanopause.12 Ketika menopause sudah mendekat, siklus dapat terjadi dalam waktu-waktu yang tidak menentu dan bukan hal yang aneh jika menstruasi tidak datang selama beberapa bulan. Pada usia empat puluh tahun, beberapa perubahan hormon yang dikaitkan dengan pra menopause mulai terjadi. ${ }^{13}$

\footnotetext{
9 Sulaiman Sastrawinata, "Wanita dalam Berbagai Masa Kehidupan", Abdul Bari Saifuddin (et. Al.), IImu Kandungan, (Jakarat: Yayasan Bina Pustaka Sarwono Prawirohardjo, 2007), 130.

${ }^{10}$ Anna Glasier dan Ailsa Gebbie, Keluarga Berencana dan Kesehatan Reproduksi, (Jakarta: EGC, 2006), 395.

I Penelitian telah membuktikan bahwa pada usia empat puluh tahun banyak wanita telah mengalami perubahan dalam kepadatan tulang dan pada usia empat puluh tahun banyak yang menstruasinya menjadi lebih sedikit atau lebih pendek waktunya dibanding biasanya, atau malah lebih banyak dan/atau lebih lama. Sekitar $80 \%$ wanita mulai tidak teratur siklus menstruasinya. Kenyataannya, hanya sekitar 10\% wanita berhenti menstruasi sama sekali tanpa disertai ketidakteraturan siklus yang berkepanjangan sebelumnya. Dalam suatu kajian yang melibatkan lebih dari 2.700 wanita, kebanyakan di antara mereka mengalami transisi pra menopause yang berlangsung antara dua hingga delapan tahun. Daru Wijayanti, Fakta Penting Seputar Kesehatan Reproduksi Wanita, (Yogyakarta: Bookmarks, 2009), | | | - | |2.

12 Anna Glasier dan Ailsa Gebbie, Keluarga Berencana dan Kesehatan Reproduksi, 395.

13 Daru Wijayanti, Fakta Penting Seputar Kesehatan Reproduksi Wanita, I 12.
} 
Pola menstruasi memperlihatkan variasi individual yang sangat besar, dan pemendekan siklus mungkin merupakan gambaran paling dini. Ovarium secara progresif semakin tidak berespon terhadap rangsangan gonadotropin disertai peningkatan konsentrasi FSH yang terdeteksi dalam fase folikel siklus. Bulanbulan amenorea sering diselingi oleh menstruasi regular walaupun biasanya terjadi pemanjangan siklus seiring dengan mendekatnya periode menstruasi terakhir. Siklus menstruasi yang lama mengindikasikan tidak adanya ovulasi dan perdarahan menstruasi berikutnya mungkin banyak, karena stimulasi berkepanjangan endometrium oleh estrogen tanpa imbangan. ${ }^{14}$

Kelainan haid sering terjadi pada masa pramenopause. Kelainan tersebut dapat bersifat oligomenorea (siklus yang panjang) atau polimenorea (siklus yang pendek). Sering juga banyaknya darah waktu haid yang berubah, sehingga dapat terjadi hipomenorea (darah haid sedikit) atau hipermenorea (menoragia), yakni darah haid yang banyak. Yang paling mengganggu ialah metroragia (perdarahan yang tidak teratur). Metroragia disebabkan oleh tidak teraturnya lagi ovulasi dalam pramenopause; jadi siklus sering bersifat anovulatoir yang dapat menyebabkan perdarahan disfungsional. ${ }^{15}$

Umur waktu terjadinya menopause dipengaruhi oleh keturunan, kesehatan umum, dan pola kehidupan. Ada kecenderungan dewasa ini untuk terjadinya menopause pada umur yang lebih tua. Misalnya, pada tahun 1915 menopause dikatakan terjadi sekitar umur 44 tahun, sedangkan pada tahun 1950 pada umur yang mendekati 50 tahun.

Menopause rupanya ada hubungan dengan menarke, makin dini menarke terjadi, makin lambat menopause timbul; sebaliknya makin lambat menarke terjadi, makin cepat menopause timbul. Pada abad ini umumnya nampak bahwa menarke makin dini

$14 \mathrm{lbid}$.

15 "Gangguan pada masa Bayi, Kanak-kanak, Pubertas, Klimakterium, dan Senium”, IImu Kandungan, (Jakarta: Yayasan Bina Pustaka, 2007), 238. 
timbul dan menopause makin lambat terjadi, sehingga masa reproduksi menjadi lebih panjang. Walaupun demikian, di negaranegara maju rupa-rupanya menarke tidak bergeser lagi ke umur yang lebih muda; tampaknya batas maksimal telah tercapai. ${ }^{16}$

\section{Amenorea dalam perspektif Medis}

Amenorea ialah keadaan tidak adanya haid untuk sedikitnya 3 bulan berturut-turut. Amenorea adalah panjang siklus haid yang memanjang dari panjang siklus haid klasik (oligomenorea) atau tidak terjadinya perdarahan haid, minimal tiga bulan berturutturut. Terjadinya amenorea dan oligomenorea seringkali mempunyai sebab yang sama. Amenorea dibedakan menjadi dua jenis:

a. Amenorea primer

Amenorea primer yaitu tidak terjadinya haid sekalipun pada wanita yang mengalami amenorea. Amenorea primer apabila seseorang seorang wanita berumur 18 tahun ke atas tidak pernah haid. ${ }^{17}$

b. Amenorea sekunder

Amenorea sekunder penderita pernah mengalami haid, tetapi kemudian tidak dapat lagi. ${ }^{18}$ Amenorea sekunder yaitu tidak terjadinya haid yang diselingi dengan perdarahan haid sesekali pada wanita yang mengalami amenorea. ${ }^{19}$

Penyebab terjadinya amenorea primer secara umum lebih berat dan sulit daripada penyebab amenorea sekunder, seperti adanya kelainan-kelainan kongenital dan genetik. Sedangkan penyebab terjadinya amenorea sekunder lebih mengarah pada sebab-sebab yang timbul kemudian dalam kehidupan wanita seperti gangguan-gangguan gizi tubuh, metabolisme tubuh, tumor, dan penyakit infeksi. ${ }^{20}$

\footnotetext{
16 Sulaiman Sastrawinata, "Wanita dalam Berbagai Masa Kehidupan”, I30.

17 Pandapotan Simanjuntak, "Gangguan Haid dan Siklusnya", IImu Kandungan, Jakarta: Yayasan Bina Pustaka Sarwono Prawirohardjo, 2007), 205.

18 lbid.

${ }^{19}$ Hendrik, Problema Haid Tinjauan Syariat Islam dan Medis, (Solo: Tiga Serangkai, 2006), 122 - 123.

$20 \mathrm{lbid}$.
} 
Istilah kriptomenorea menunjuk kepada keadaan di mana tidak tampak adanya haid karena darah tidak keluar berhubung ada yang menghalangi, misalnya pada ginatresia himenalis, penutupan kanalis servikalis, dan lain-lain. Selanjutnya ada pula amenorea fisiologik, yakni yang terdapat dalam masa sebelum pubertas, masa kehamilan, masa laktasi, dan sesudah menopause.

\section{Kehamilan dalam perspektif Medis}

Kehamilan tejadi dengan konsepsi (pembuahan) dan berakhir dengan permulaan persalinan. Persalinan ialah proses pengeluaran bayi dan uri dari badan ibu. ${ }^{21}$ Lamanya kehamilan yang normal adalah 280 hari atau 40 minggu dihitung dari hari pertama haid yang terakhir. Kadang-kadang kehamilan berakhir sebelum waktunya dan ada kalanya melebihi waktu yang normal. Berakhirnya kehamilan sebelum anak dapat hidup di dunia disebut abortus. ${ }^{22}$

Abortus dapat dibagi sebagai berikut:

1. Abortus spontan, aborus yang terjadi dengan sendirinya atau karena keguguran.

2. Abortus provocatus (disengaja, digugurkan):

a. abortus provocatus artivicialis (therapeuticus): Pengguguran kehamilan biasanya dengan alat-alat dengan alasan bahwa kehamilan membahayakan dan bisa menyebabkan kematian bagi ibu.

b. abortus provocatus criminalis: Penggguran kehamilan tanpa alasan medis yang sah dan dilarang oleh hukum.

Terdapat beberapa istilah klinis dalam abortus:

1. Abortus imminens (keguguran mengancam). Abortus ini baru mengancam dan masih ada harapan untuk mempertahankannya

\footnotetext{
2l Tim Bagian Obstetri dan Ginekologi Fakultas Kedokteran Universitas Padjajaran, Obstetri Fisiologi, (Bandung: Universitas Padjajaran, 1983), 3.

22 Anak baru mungkin hidup di dunia kalau beratnya telah mencapai 1000 gram atau umur kehamilan 28 mingggu. Ada juga yang mengambil sebagai batas untuk abortus berat anak yang kurang dari 500 gram. Jika anak yang lahir beratnya antara 500 dan 900 gram disebut abortus immaturus.
} 
2. Abortus incipens (keguguran berlangsung). Abortus ini sudah berlangsung dan tidak dapat dicegah lagi.

3. Abortus incompletus (keguuran tidak lengkap). Sebagian dari buah kehamilan telah dilahirkan tapi sebagian (biasanya jaringan plasenta) masih tertinggal di dalam rahim.

4. Abortus completus (keguguran lengkap). Seluruh buah kehamilan telah dilahirkan dengan elengkap.

5. Missed abortion (keguguran tertunda). Missed abortion ialah keadaan di mana janin telah mati sebelum minggu ke 22, tetapi tertahan di dalam rahim selama 2 bulan atau lebih setelah janin mati.

6. Abortus habitualis (keguguran berulang-ulang) ialah abortus yang telah berulang dan berturut turut terjadi. ${ }^{23}$

\section{Pengertian Iddah}

Kata iddah dalam al-Qur'an disebut sebanyak 11 kali, baik dihubungkan dengan kata ganti (dhamir) atau tidak. Kata iddah yang disebut secara terpisah terdapat dalam QS. al-Baqarah (2): 184, 185; QS. at-Taubah (9): 36, 37; QS. al-Ahzab (33): 49; QS. ath-Thalaq (65): 1 . Sementara kata iddah yang dihubungkan dengan kata ganti, baik jamak untuk perempuan (hunna) maupun jamak untuk lakilaki (hum), terdapat di dalam QS. ath-Thalaq (65): 1, 4; QS. al-Kahfi (18): 22; QS. al-Muddatstsir (74): 31.

Dalam ayat-ayat tersebut, kata iddah memiliki beberapa makna yang berbeda, yaitu: (a) mengganti jumlah puasa Ramadhan yang ditinggalkan (QS. 2: 184-185); (b) jumlah bulan (QS. 9: 36-37); (c) jumlah waktu yang harus dilalui (masa tunggu) pasca perceraian bagi istri sebelum menikah lagi (QS. 33: 49, QS. 65: 1,4); (d) jumlah penghuni gua (QS. 18: 22); (e) jumlah malaikat (QS. 74: 31).24

Iddah yang menjadi objek kajian dalam artikel ini adalah iddah dalam pengertian masa tunggu bagi istri pasca perceraian sebelum menikah lagi. Untuk memerintahkan perempuan agar menunggu

\footnotetext{
${ }^{23}$ Tim Bagian Obstetri dan Ginekologi Fakultas Kedokteran Universitas Padjajaran, Obstetri Patologi, (Bandung: Universitas Padjajaran, 1984), 7-8.

${ }^{24}$ Muhammad Isna Wahyudi, Fiqh Iddah Klasik dan Kontemporer, (Yogyakarta: LkeS, 2009), 73.
} 
selama masa iddah tersebut, al-Qur'an menggunakan kata kerja tarabbasha yatarabbashu seperti yang terdapat di dalam QS. alBaqarah (2): 228, 234. Kata kerja tarabbasha-yatarabbashu juga terdapat dalam QS. at-Taubah (9): 98 dan QS. al-Nisa' (4): 141 yang memiliki arti menunggu. Adapun bentuk mashdar dari kata kerja tersebut yaitu tarabbashu dapat dijumpai dalam QS. al-Baqarah (2): 226, yang menjelaskan tenggang waktu bagi suami yang melakukan îlâ' (bersumpah tidak mencampuri istrinya), yaitu selama empat bulan. Selama masa tersebut berakhir, maka suami harus memilih antara kembali kepada istrinya atau menceraikannya.

Jika dikaji secara etimologis, kata iddah berasal dari kata kerja adda-yauddu yang berarti menghitung sesuatu (ihshâ al-syai). Adapun kata iddah memiliki arti seperti kata al-adad yaitu ukuran dari sesuatu yang dihitung atau jumlahnya. Jika kata iddah tersebut dihubungkan dengan kata al-mar'ah (perempuan), maka artinya hari-hari haid/sucinya, atau hari-hari ihdadnya terhadap pasangannya atau hari-hari ihdadnya terhadap pasangannya atau hari-hari menahan diri dari memakai perhiasan, baik berdasarkan bulan, haid/suci, atau melahirkan. ${ }^{25}$

Secara istilah, para ahli fikih merumuskan definisi iddah dengan berbagai ungkapan. Dalam redaksi yang berbeda, berbagai ungkapan tersebut memiliki kesamaan secara garis besarnya. Iddah adalah masa tunggu seorang perempuan yang tidak hanya didasarkan pada masa haid atau sucinya, tetapi juga didasarkan pada bulan atau dengan melahirkan. Selama masa tersebut, seorang (perempuan) dilarang untuk menikah dengan laki-laki lain. Iddah berarti sejumlah nama bagi masa lamanya untuk menunggu bagi perempuan dan tidak boleh untuk menikah setelah wafat suaminya atau berpisah dengannya. Kewajiban iddah hanya berlaku bagi perempuan dengan tujuan untuk mengetahui kebersihan rahim, beribadah ( $\left.t a^{\prime} a b b u d\right)$ maupun berkabung (tafajju') atas kematian

25 lbid., 74.

\begin{tabular}{l|l}
112 & $\begin{array}{l}\text { al-Daulah } \\
\text { Vol. 8. No. 1. April } 2018\end{array}$
\end{tabular} 
suaminya, yang selama masa tersebut perempuan (istri) dilarang menikah dengan laki-laki lain. ${ }^{26}$

\section{Macam-Macam Iddah}

Dari berbagai ayat al-Qur'an yang mengatur tentang iddah, maka iddah dapat dibedakan menjadi: (a) iddah dengan ukuran haid atau suci (al-aqrâ'). Iddah dalam kategori ini berkaitan dengan iddah istri yang dicerai hidup dan masih haid serta telah melakukan hubungan suami istri (dukhûl). ${ }^{27}$ (b) iddah dengan hitungan bulan. Ada beberapa kondisi bagi istri yang menempuh masa iddah berkaitan dengan iddah dilihat dari hitungan bulan. Istri yang ditinggal mati suaminya, walaupun belum pernah melakukan hubungan suami istri (dukhûl), masih kecil atau dewasa, bahkan telah menopause, diwajibkan menempuh masa iddah selama 4 bulan 10 hari sebagaimana dalam firman Allah QS. al-Baqarah (2): 234, kecuali istri yang ditinggal mati itu diwajibkan menempuh masa iddah selama hamil, maka iddahnya sampai melahirkan. Iddah dilihat dari hitungan bulan juga terdapat pada kasus yang lain yakni iddah istri yang dicerai karena belum baligh atau karena telah memasuki masa menopause. Istri dalam kondisi ini sebagaimana dalam QS. al-Thalaq (65): 4 diwajibkan menempuh masa iddah selama 3 bulan. ${ }^{28}$ (c) iddah dengan melahirkan. Iddah yang dilihat sampai melahirkan yakni iddah istri yang dicerai suaminya dalam keadaan hamil. Wanita dalam kondisi ini seperti dalam QS. ath-Thalaq (65): 4 diwajibkan menempuh masa iddah sampai melahirkan. ${ }^{29}$ Kalau dicermati, penentuan iddah yang demikian itu sebenarnya disesuaikan dengan sebab perceraian maupun keadaan istri ketika terjadi perceraian, karena putusnya perkawinan dapat dibedakan karena kematian suami dan talak. Sedangkan kondisi istri dapat dibedakan menjadi istri yang sudah dicampuri atau belum, istri yang masih mengalami haid atau belum

\footnotetext{
${ }^{26}$ Indar, "Iddah dalam Keadilan Gender", Yinyang, I08- 109.

27 Abdul Helim, "Membaca Kembali Doktrin Iddah dalam Perspektif Ushûl al-Fiqh", 282.

28 Ibid., 283.

29 lbid., 284.
} 
atau bahkan sudah menopause), dan istri dalam keadaan hamil atau tidak. ${ }^{30}$

Iddah dalam Undang-Undang Perkawinan dan Kompilasi Hukum Islam

Selain dalam al-Qur'an dan hadis, iddah juga diatur dalam undang-undang perkawinan, yaitu Undang-Undang No 1 tahun 1974 Pasal 29 tentang Perkawinan yang berbunyi:

1. Waktu tunggu bagi seorang janda sebagai dimaksud dalam pasal

11 ayat 2 Undang-Undang ditentukan sebagai berikut:

a. Apabila perkawinan putus karena kematian, waktu tunggu ditetapkan 130 (seratus tiga puluh) hari.

b. Apabila perkawinan putus karena perceraian waktu tunggu bagi yang masih haid ditetapkan 3 (kali) suci dengan sekurang kurangnya 90 (sembilan puluh) hari, dan bagi yang tidak berdatang bulan ditetapkan 90 (sembilan puluh) hari.

c. Apabila perkawinan putus sedang janda tersebut sedang dalam keadaan hamil, waktu tunggu ditetapkan sampai melahirkan.

2. Tidak ada waktu tunggu bagi janda yang putus perkawinan karena perceraian sedang antara janda tersebut dengan bekas suaminya belum pernah terjadi hubungan kelamin.

3. Bagi perkawinan yang putus karena perceraian, tenggang waktu tunggu dihitung sejak jatuhnya putusan pengadilan yang mempunyai kekuatan hukum yang tetap, sedangkan bagi perkawinan yang putus karena kematian, tenggang waktu tunggu dihitung sejak kematian suami. 
Mengenai waktu tunggu dalam KHI Pasal 153 yang berbunyi:

Bagian I

Kedua Waktu Tunggu

Pasal 153

(1) Bagi seorang istri yang putus perkawinannya berlaku waktu tunggu atau iddah, kecuali qabla dukhûl dan perkawinannya putus bukan karena kematian suami.

(2) Waktu tunggu bagi seorang janda ditentukan sebagai berikut:

a. Apabila perkawinan putus karena kematian, walaupun qabla al-dukhûl, waktu tunggu ditetapkan 130 hari.

b. Apabila perkawinan putus karena perceraian waktu tunggu bagi yang masih haid ditetapkan 3 kali suci dengan sekurang kurangnya 90 hari, dan bagi yang tidak haid ditetapkan 90 hari.

c. Apabila perkawinan putus karena perceraian sedang janda tersebut dalam keadaan hamil, waktu tunggu ditetapkan sampai melahirkan.

d. Apabila perkawinan putus karena kematian sedang janda tersebut dalam keadaan hamil, waktu tunggu ditetapkan sampai melahirkan.

(3) Tidak ada waktu tunggu bagi yang putus perkawinan karena perceraian sedang antara janda tersebut dengan bekas suaminya qabla al-dukhûl

(4) Bagi perkawinan yang putus karena perceraian, tenggang waktu tunggu dihitung sejak jatuhnya putusan pengadilan agama yang mempunyai kekuatan hukum tetap, sedangkan bagi perkawinan yang putus karena kematian, tenggang waktu tunggu dihitung sejak kematian suaminya.

(5) Waktu tunggu bagi istri yang pernah haid sedang pada waktu menjalani iddah tidak haid karena menyusui, maka iddahnya tiga kali waktu suci.

(6) Dalam hal keadaan pada ayat (5) bukan karena menyusui, maka iddahnya selama satu tahun, akan tetapi bila dalam 
waktu satu tahun tersebut ia berhaid kembali, maka iddahnya menjadi tiga kali waktu suci. ${ }^{31}$

\section{Tafsir Ayat QS. al-Thalaq (65): 4}

Dalam penelitian ini, kajian difokuskan pada kajian iddah dalam QS. al-Thalaq (65): 4, yang menjelaskan tentang iddah bagi wanita menopause, amenorea dan istri dalam keadaan hamil:

Wa al-lâî yaisna min al-mahîdhi min nisâikum in irtabtum fa iddatuhunna tsalâtsatu asyhurin wa al-lâî lam yahidhna wa ûlâtu al-ahmâli ajaluhunna an yadha'na hamlahunna wa man yattaqillâha yaj'al lahû min amrihî yusron

4. Dan perempuan-perempuan yang tidak haid lagi (monopause) di antara perempuan-perempuanmu jika kamu ragu-ragu (tentang masa iddahnya), maka masa iddah mereka adalah tiga bulan; dan begitu (pula) perempuan-perempuan yang tidak haid. Dan perempuan-perempuan yang hamil, waktu iddah mereka itu ialah sampai mereka melahirkan kandungannya. Dan barang -siapa yang bertakwa kepada Allah, niscaya Allah menjadikan baginya kemudahan dalam urusannya.

Ketentuan iddah dengan haid diatur dalam QS. al-Baqarah 228, sedangkan ayat ini menjelaskan tentang ketentuan iddah dengan bulan yang dikhususkan bagi wanita yang tidak haid, baik karena menopause atau amenorea, dan wanita hamil. ${ }^{32}$

Menurut Wahbah al-Zuhaily, kalimat wa allâi yaisna min almahîdh diperuntukkan bagi wanita menopause karena tua. ${ }^{33}$ Menurut Wahbah al-Zuhaily, iddah wanita menopause yang sudah terputus haidnya ketika tua sekitar usia 55 atau 60 tahun iddahnya

\footnotetext{
31 Undang-undang Perkawinan di Indonesia dilengkapi Kompilasi Hukum Islam, (Surabaya: Arkola, tt.), 228-229.

32 Muhammad Ali al-Shabuni, Tafsîr Âyât al-Ahkâm, Juz 2, (Beirut: Dâr al-Kutub al-'Ilmiyyah, t.t.), 44I.

33 Wahbah al-Zuhaili, al-Tafsîr al-Munîr, juz 28, (Beirut: Dâr al-Fikr, I99I ), 279.
} 
3 bulan sebagai ganti 3 qurú' bagi yang haid, begitu juga anak kecil yang belum haid. ${ }^{34}$

Dalam ayat ini, ulama berselisih pendapat tentang makna "in irtabtum" (jika kalian ragu):

Al-Jashshash Mujahid, Ikrimah, dan Qatadah mengartikan bahwa maksud dari kalimat tersebut adalah jika seorang wanita masih ragu dengan menopausenya, maka ia tidak boleh beriddah dengan tiga bulan. Wanita yang demikian termasuk wanita istihadhah, karena maksud ragu adalah apakah ia ragu darah haid atau darah penyakit.

Al-Zujaj mengartikan "in irtabtum" dengan "jika kalian ragu dalam haidnya dan telah terputus haidnya dan kalian termasuk orang yang haid". ${ }^{35}$ Wahbah al-Zuhailiy menafsirkan "in irtabtum" dengan ragu dalam iddah atau tidak tahu. ${ }^{36}$

Sedangkan kalimat wa allâi lam yahidhna, al-Qurtuby dan Wahbah sepakat menunjukkan ayat tersebut bagi anak perempuan (al-saghîrât $)^{37}$, yang biasanya belum haid, maka iddahnya 3 bulan. Ketika di tengah iddah dia mengalami haid, maka iddahnya berubah menjadi haid, begitu juga bagi wanita menopause, jika iddahnya ketika dia haid lalu menopause, maka berubah hitungannya dari haid ke bulan. ${ }^{38}$

Dari beberapa landasan hukum di atas dapat dipahami bahwa iddah bagi wanita yang belum haid pada dasarnya disamakan dengan iddah wanita yang sudah berhenti haid (menopause). Iddah wanita tersebut adalah dengan hitungan bulan, yaitu tiga bulan.

\section{Pandangan Fukaha tentang Problematika Iddah Wanita Menopause, Wanita tidak Haid, Wanita Wanita Hamil}

Dalam fikih, wanita haid dan melahirkan berpengaruh pada hitungan iddahnya, jika ia dicerai suaminya atau ditinggal mati

\footnotetext{
34 bid., 280 .

35 Muhammad Ali al-Shabuni, Tafsîr Ayât al-Ahkâm, Juz 2, 447.

${ }^{36}$ Wahbah al-Zuhaili, al-Tafsîr al-Munîr, Juz 28, 279.

37 lbid.

${ }^{38}$ Wahbah al-Zuhaili, al-Tafsîr al-Munîr, Juz 28, 283. Lihat juga al-Qurthubi, al-Jâmi' li Ahkâm alQur'ân, Juz I8, (Beirut: Dâr al-Kutub al-Ilmiyyah, 1993), 109.
} 
suaminya. Dalam hal ini, hitungan iddahnya dihitung dengan jumlah haidnya. Timbul permasalahan yang rumit, jika seorang wanita tidak memiliki jadwal haid yang lancar, karena lancar tidaknya haid seorang wanita berpengaruh pada hukum iddahnya, seperti iddah wanita yang mengalami menopause dini, iddah wanita yang mengalami keguguran, iddah bagi wanita yang tidak lancar haidnya, atau iddah wanita yang mengalami istihadah dan iddah wanita yang masih kecil.

Perbedaan tersebut timbul dikarenakan perbedaan penafsiran tentang haid dan tidak haid dalam ayat al-Qur'an yang menjelaskan masa iddah. Bahwa wanita haid iddahnya tiga qur $\hat{u}^{\prime}, 39$ yang tidak haid karena belum haid atau menopause iddahnya tiga bulan, sedangkan wanita hamil adalah sampai melahirkan.

Berikut beberapa pandangan ulama terhadap beberapa permasalahan iddah yang berkaitan dengan menopause, amenorea dan kehamilan:

1. Iddah bagi wanita yang tidak lancar haidnya karena penyakit

Bagi yang terhenti haidnya karena penyakit, menurut Malik iddahnya satu tahun, sedangkan yang terhenti karena menyusui, maka menurut Malik menunggu satu tahun setelah masa menyusui selesai (dua tahun). ${ }^{40}$ Menurut Malik, Ibn al-Qasim, Abdullah bin Asbagh, bagi wanita yang tidak lancar haidnya karena penyakit maka iddahnya 9 bulan ditambah 3 bulan (satu tahun). Asyhab mengatakan: seperti wanita yang menyusui dan menyapih dengan haid atau dengan tahun. Diriwayatkan bahwa Hibban bin Munqiz

39 Hikmah dari iddah tiga bulan atau tiga quru' adalah bahwa hal tersebut untuk memastikan ketidakhamilan seorang wanita, akrena biasanya pada kehamilan awal (trimester pertama) merupakan kehamilan yang masih lemah sehingga rawan keguguran yang biasanya ditandai dengan perdarahan. Jika seorang wanita tidak mengetahui kehamilannya, sering mengira bahwa perdarahan atau bercak darah tersebut adalah haid. Biasanya kehamilan bisa dipastikan pada bulan keempat sesuai dengan masa iddah wanita yang ditinggal mati suaminya yaitu empat bulan sepuluh hari. Bahwa wanita bisa merasa yakin ia hamil apabila sudah memasuki bulan keempat, maka apabila telah melewati tiga quru' atau tiga kali haid bisa dipastikan ia tidak hamil. NurLailatul Musyafa'ah, "Relevansi antara Medis dan Fikih tentang Perdarahan pervaginam", Jurnal Studi Gender Indonesia, Volume 05, Nomor 02, November 2016, 153.

40 Wahbah al-Zuhaili, al-Tafsîr al-Munîr, juz 28, 282. 
menceraikan istrinya yang menyusui dan tidak haid selama satu tahun lalu Hibban sakit dan ia khawatir akan mewarisinya, maka Hibban menghadap Ali dan Zaid dan keduanya mengatakan bahwa perempuan tersebut berhak atas warisannya karena ia bukan anakanak. Maka ketika Hibban meninggal, wanita tersebut mewarisinya dan beriddah atas kematian suaminya. ${ }^{41}$

2. Iddah wanita yang terhenti haidnya bukan karena penyakit atau menyusui

Bagi yang terlambat haidnya bukan karena sakit atau menyusui, ia menunggu satu tahun jika tidak haid akumulasi dari 9 bulan ditambah 3 bulan. Begitu juga bagi perempuan yang ragu dalam hitungan iddahya, ia tidak boleh menikah sampai hilang keraguannya. Yang menurut Maliki dan Hanabilah: keraguan itu akan hilang dengan iddah satu tahun sebagai akumulasi iddah wanita hamil 9 bulan dan iddah 3 bulan. Sedangkan Hanafi dan Syafii berpendapat bahwa iddahnya adalah menunggu sampai ia haid lagi atau sampai usia wanita menopause pada umumnya, kemudian ditambah 3 bulan. ${ }^{42}$

Dalam Tafsir al-Qurtuby juga dijelaskan bahwa bagi wanita yang terlambat haidnya bukan karena penyakit dan bukan menyusui, maka masa iddahnya adalah satu tahun. Hal tersebut bagi yang tidak ragu akan kehamilannya. Jika ragu hamil maka menunggu 4, 5, 6, 7 tahun. Al-Masyhur mengatakan 5 tahun, karena jika janin mungkin berada di dalam kandungan 1 tahun tahun, maka kemungkinan juga bisa bertahan selama 5 tahun. ${ }^{43}$

3. Iddah wanita mustahâdhah

Mustahâdhah adalah perempuan yang mengeluarkan darah tanpa henti. Darah ini tidak menghalangi shalat sebagaimana darah haid yang keluar dapat membatalkan shalat. Jika terjadi perceraian antara seorang istri dengan suaminya, dan ia mempunyai kebiasaan (lamanya haid) iddah sesuai dengan kebiasaannya itu, ini sesuai

\footnotetext{
${ }^{4 \mid}$ al-Qurthubi, al-Jâmi' li Ahkâm al-Qur'ân, Juz I 8, 109.

${ }^{42}$ Wahbah al-Zuhaili, al-Tafsîr al-Munîr, Juz 28, 282.

43 al-Qurthubi, al-Jâmi' li Ahkâm al-Qur'an, juz 18, 109.
} 
dengan kesepakatan ulama. Namun, jika ia tidak mempunyai kebiasaan yang diketahui atau mempunyai kebiasaan tetapi ia lupa, perempuan ini dinamakan dengan (perempuan yang bingung), maka dalam hal ini ada pendapat yang mengatakan, bahwa ia harus beriddah selama tiga bulan. Sebab, biasanya haid itu jatuh pada setiap bulan. Sementara, menurut satu pendapat, ia harus beriddah selama tujuh bulan, satu bulan untuk ketika haid, sementara enam bulan lainnya untuk ketiga masa suci, sebagai sikap hati-hati. Menurut pendapat yang lain lagi, ia harus beriddah selama tiga bulan, selain bulan di mana terjadi perceraian pada bulan itu. Dan ada juga yang berpendapat, ia harus beriddah selama satu tahun. Sementara praktik yang berlaku sesuai dengan pendapat pertama. Dapat dipahami bahwa iddah bagi perempuan yang mustahâdhah ini memiliki beragam pendapat. Namun yang terpenting adalah melihat pada pendapat jumhur ulama, bahwa iddahnya adalah selama tiga bulan. Ketika habis masa iddahnya, maka ia berhak untuk menikah kembali dengan laki-laki lainnya, sebagaimana juga berlaku untuk habisnya masa dengan tiga kali suci, hamil dan kematian suami. ${ }^{44}$

Menurut Ibn al-Musayyab dan al-Laits, iddah wanita mustahâdhah yang dicerai suami atau ditinggal mati suaminya adalah satu tahun, meskipun wanita tersebut mengerti jenis dan hari-hari haid di antara masa istihadhahnya. Menurut Malik, satu tahun ( 9 bulan ditambah 3 bulan). Menurut Abu 'Umar, jika wanita tersebut mengenali jenis darah dan mengetahui masa haid di antara masa istihadahnya maka dihitung tiga qurû'. ${ }^{5}$ Seorang mufti dari mazhab Hanafi berpendapat bahwa iddahnya 7 bulan (6 bulan dianggap masa suci dan satu bulan sebagai masa haid).

Syafi'i dan Hanabilah: iddah mustahâdhah sama seperti wanita menopause yaitu 3 bulan, sebagaimana hadis Rasulullah bahwa

\footnotetext{
${ }^{44}$ Jamhuri dan Izzudin Juliara, "Penggabungan Iddah Wanita Hamil dan Kematian Suami (Analisis terhadap Pendapat Mazhab Syafi'i)", Samarah: Jurnal Hukum Keluarga dan Hukum Islam, Volume I, Nomor I, (Tahun 2017), 237.

45 lbid.
} 
Hamnah binti Jahsy disuruh Rasulullah menunggu (menghitung haidnya) 6-7 hari setiap bulannya, maka setiap bulan dianggap haid satu kali. ${ }^{46}$

4. Hukum wanita muda yang sudah tidak haid

Para ulama sepakat bahwa iddah bagi perempuan yang tidak haid, baik karena masih kecil atau sudah tidak haid (menopause), apabila ia dicerai oleh suaminya maka ia beriddah selama 3 bulan. Akan tetapi bagi wanita yang dicerai oleh suaminya dalam keadaan masih haid kemudian tidak mengalami haid lagi sedangkan ia masih berada dalam usia haid, maka para ulama memberikan alasan yang berbeda.

Menurut Imam Malik, iddah bagi wanita yang tidak mengalami haid sedang ia masih dalam usia haid dan tidak ada keraguan adanya kehamilan atau sebab lain (menyusui atau sakit), maka istri tersebut harus menunggu selama 9 bulan. Jika dalam masa tersebut istri tidak mengalami haid, maka ia menjalani iddah selama 3 bulan. Pendapat Imam Malik ini berdasarkan atsar Umar bin Khattab. Sedangkan menurut Imam Syafi'i dan Hanafi, iddah bagi wanita yang berhenti haidnya, sedangkan ia masih dalam usia haid ia harus menunggu sehingga memasuki usia putus haid. Perbedaan pendapat ini dikarenakan perbedaan para ulama dalam memahami firman Allah dalam surat ath-Thalaq ayat 4. Mazhab Hanafi mengartikan kata yaisna adalah wanita yang sudah putus haid. Bagi wanita yang berhenti haidnya sedang ia masih mungkin mengalami haid, maka ia harus menunggu sampai ia memasuki usia tersebut (usia putus haid). Menurut Ahmad dan Ishaq mengenai seorang wanita yang masih muda namun sudah tidak mengalami haid, jika berhentinya haid karena tidak hamil, maka masa iddahnya adalah satu tahun; 9 bulan sebagaimana iddah wanita hamil ditambah 3 bulan sebagai iddah wanita tidak haid. Hal ini berlaku juga bagi wanita yang ketika dicerai kemudian dia haid satu kali atau dua kali kemudian haidnya berhenti, maka masa iddahnya ditambah satu tahun lagi. Menurut Hanafi, iddah wanita

${ }^{46}$ Wahbah al-Zuhaili, al-Tafsîr al-Munîr, Juz 28, 283. 
yang masih muda namun sudah tidak mengalami haid tetap dihitung tiga kali haid, meskipun ia haid dua puluh tahun kemudian, sampai ia benar-benar memasuki masa menopouse maka iddahnya dihitung 3 bulan. Wanita tersebut termasuk murtâbah (dalam kondisi ragu antara masa subur atau menopause) ${ }^{47}$

5. Iddah wanita keguguran

Apabila terjadi perceraian ketika isteri sedang hamil menurut kesepakatan ulama masa seorang isteri secara langsung berakhir dengan melahirkan kandungan. Hal itu berdasarkan firman Allah dalam surat at-Thalaq sebagai berikut:

Dan perempuan-perempuan yang tidak haid lagi (menopause) di antara perempuan-perempuanmu jika kamu ragu-ragu (tentang masa iddahnya), maka masa iddah mereka adalah tiga bulan; dan begitu (pula) perempuan-perempuan yang tidak haid. Dan perempuanperempuan yang hamil, waktu mereka itu ialah sampai mereka melahirkan kandungannya. Dan barangsiapa yang bertakwa kepada Allah, niscaya Allah menjadikan baginya kemudahan dalam urusannya. (QS. Ath-Talak: 4).

Menurut al-Shabuni, perempuan yang hamil iddahnya habis karena melahirkan anak, baik dicerai suaminya atau suaminya mati. Terhadap iddah wanita hamil dan ditinggal mati suaminya, masih menuai perbedaan pendapat. Quraish Syihab dalam al-Mishbah berpendapat bahwa iddah wanita yang ditinggal mati, sedangkan ia dalam keadaan hamil adalah masa yang terpanjang dari kedua pesan ayat al-Baqarah dan at-Thalaq. Kalau ia melahirkan sebelum empat bulan sepuluh hari, maka ia harus menyempurnakan masa iddah itu, tetapi kalau berlanjut melebihi empat bulan sepuluh hari, maka ia harus melanjutkannya sampai melahirkan. Pendapat ini dianut oleh Imam Abu Hanifah. Berbeda dengan pendapat Sayyidina Ali ra tersebut, lebih lanjut Quraish Shihab mengatakan

47 al-Qurthubi, al-Jâmi' li Ahkâm al-Qur'ân, Juz I 8, 109.

\begin{tabular}{l|l}
122 & $\begin{array}{l}\text { al-Daulah } \\
\text { Vol. 8. No. 1. April } 2018\end{array}$
\end{tabular} 
bahwa banyak ulama yang menetapkan masa iddah wanita yang hamil berakhir dengan kelahiran janinnya, bukan masa empat bulan sepuluh hari.

Pendapat juga dikuatkan oleh hadis yang menyatakan bahwa Harits meninggal suaminya sedang ia dalam keadaan hamil. Ia melahirkan anaknya setelah lima belas hari (dalam riwayat lain setelah empat puluh hari) setelah kematian itu kemudian datang kepada Rasulullah saw meminta izin untuk kawin. Kemudian Rasul bersabda:

Abu Hurairah berselisih dengan Ibnu Abbas mengenai seorang wanita yang ditinggal mati suaminya apabila ia telah melahirkan. Abu Hurairah berpendapat, "Ia boleh dinikahi." Sedangkan Ibnu Abbas berpendapat, "Waktu yang paling lama." Kemudian mereka mengirim utusan kepada Ummu Salamah (untuk menanyakan hal tersebut), kemudian Ummu Salamah berkata, "Suami Subai'ah meninggal, lalu lima belas hari kemudian ia melahirkan." Ummu Salamah melanjutkan, "Kemudian ada dua orang laki-laki yang meminangnya, lalu ia menaruh perhatian kepada salah seorang dari kedua laki-laki tersebut. Maka ketika mereka khawatir Subai'ah menjatuhkan pilihannya, mereka pun berkata, "Sesungguhnya engkau belum halal (untuk nikah)." Ummu salamah berkata, "Maka aku pergi menemui Rasulullah saw untuk menanyakan hal tersebut, beliau lalu menjawab: "Sungguh engkau telah halal, maka menikahlah dengan orang yang engkau kehendaki."

Syarat kelahiran yang dapat mengakhiri masa iddah menurut sebagian ulama yaitu hendaknya anak yang dilahirkan telah jelas bentuk atau sebagian bentuknya, artinya sudah tampak jelas bentuk manusia. Sebab, jika tidak ada kejelasan pada penciptaan anak, maka tidak dapat diketahui tentang keberadaannya sebagai kehamilan. Isteri mungkin saja mengandung anak dan mungkin pula potongan tidak bergerak yang berada dalam rahimnya. Begitu juga menurut Ibnu Katsir, Abu Hanifah dan Syafii bahwa iddah wanita hamil berakhir saat melahirkan janin yang dikandung, dan yang dimaksud janin yaitu mencakup bayi yang dilahirkan dan 
sudah memiliki wujud manusia. ${ }^{48}$ Sebagian ulama berpendapat bahwa iddah wanita hamil adalah selesai dengan keluarnya kehamilan, baik ia cerai talak atau cerai ditinggal mati suaminya. Menurut Maliki meskipun kehamilannya masih berbentuk alaqah dan mudghah. ${ }^{49}$

\section{Reinterpretasi Ayat tentang Iddah dalam Al-Qur'an, 65:4 dengan Pendekatan Medis}

Haid dalam fikih berimplikasi pada penghitungan masa iddah, sebagaimana dijelaskan pada QS. 65:4.

"Dan wanita yang tidak haid lagi (monopause) di antara istrimu, jika kamu ragu (tentang masa iddahnya), maka masa iddah mereka adalah tiga bulan; dan begitu (pula) wanita yang tidak haid, dan wanita yang hamil, waktu iddah mereka itu ialah sampai mereka melahirkan kandungannya, dan barangsiapa yang bertakwa kepada Allah, niscaya Allah menjadikan baginya kemudahan dalam urusannya." 50

Para fukaha sepakat bahwa ayat tersebut menjelaskan tentang masa iddah bagi wanita yang tidak haid, baik karena masih kecil atau karena menopause, bahwa iddah mereka adalah tiga bulan. ${ }^{51}$ Selain itu dijelaskan pula masa iddah bagi wanita hamil, yang masa iddahnya akan selesai dengan melahirkan. Kesepakatan tersebut berdasarkan pada sebab turunnya ayat al-Qur'an, 65:4 bahwa setelah turun ayat al-Qur'an, 2:228, tentang iddah bagi wanita yang ditalak suaminya ${ }^{52}$ dan ayat al-Qur'an, 2:231, yang menjelaskan tentang iddah bagi wanita yang ditinggal mati oleh suaminya53, Ubay bin Ka'b berkata kepada Rasulullah: "Wahai Rasul, terdapat beberapa kondisi wanita yang belum tersebut dalam ayat tersebut", Rasul bertanya: "Siapa mereka?", Ubay menjawab: “Anak-anak,

\footnotetext{
48 Jamhuri dan Izzudin Juliara, "Penggabungan Iddah Wanita Hamil dan Kematian Suami (Analisis terhadap Pendapat Mazhab Syafi'i)", 232-233.

49 Wahbah al-Zuhaili, al-Tafsîr al-Munîr, Juz 28, 283. Lihat juga al-Qurthubi, al-Jâmi' li Ahkâm alQur'ân, Juz 18, 109.

${ }^{50}$ Departemen Agama RI, Mushaf al-Qur'an Terjemah, 559.

5I Su'ad Ibrahim Shalih, Adhwâ' 'alâ Nidzâm al-Usrah fi al-Islâm, (Zaitun: Dâr al-Dhiyâ', 1996), 189.

${ }^{52}$ Iddahnya adalah tiga qurû'.

53 Iddahnya adalah empat bulan sepuluh hari.
} 
wanita tua, dan wanita hamil", maka turunlah ayat ke4 dari surat ath-Thalaq tersebut.

Dari ayat tersebut, fukaha berselisih pendapat tentang iddah bagi wanita yang mengalami menopause dini, iddah wanita yang mengalami keguguran, iddah bagi wanita yang tidak lancar haidnya, atau iddah wanita yang mengalami istihadah dan iddah wanita yang masih kecil. ${ }^{54}$

Ayat al-Qur'an, 65:4 tersebut menyebutkan iddah wanita yang tidak haid secara berurutan adalah iddah wanita menopause, iddah wanita yang belum haid, dan iddah wanita yang hamil. Dengan pendekatan medis, urutan ayat tersebut mengandung hikmah, di antaranya: Pertama, pensifatan kalimat "in irtabtum" (jika kalian ragu) dalam wanita menopause, sesuai dengan penelitian medis tentang wanita menopause bahwa sebelum menopause terdapat fase perimenopause, yang biasanya ditandai dengan siklus haid yang tidak teratur. Wanita dianggap menopause, ketika haidnya minimal telah terhenti selama 1 tahun. Dari penafsiran dengan pendekatan medis tersebut, iddah tiga bulan tidak hanya berlaku bagi wanita menopause saja, tetapi juga berlaku bagi wanita perimenopause. .5

Kedua, Penyebutan "wa al-lâi lam yahidhna" (dan wanita yang tidak haid) setelah penjelasan menopause. Urutan tersebut mengandung hikmah bahwa kalimat tersebut berlaku bagi semua wanita yang belum haid setelah bercerai, baik karena masih kecil atau karena hal lain. ${ }^{56}$ Secara rasional, seharusnya penyebutan ayat ini lebih dahulu daripada penyebutan wanita menopause, tetapi ternyata terkandung hikmah dari maksud urutan tersebut bahwa secara medis, wanita tidak haid (amenorea) dibagi menjadi dua

\footnotetext{
54 Jika wanita tersebut belum pernah haid, maka iddahnya 3 bulan, namun jika dalam masa iddahnya dia mengalami haid, maka iddahnya berubah menjadi tiga qurû'. Ibid., 360-364.

55 Iddah tiga bulan tersebut sesuai dengan haid tiga kali bagi mayoritas wanita.

56 Dalam menafsirkan ayat ini, mufassir bersepakat bahwa wanita yang dimaksud dalam ayat tersebut adalah wanita yang belum pernah haid. Muhammad 'Ali al-Shabuni, Tafsîr Ayât al-Ahkâm, Juz II, 444.
} 
yaitu amenorea primer (wanita yang belum pernah haid) ${ }^{57}$ dan amenorea sekunder (wanita yang pernah haid, tetapi terhenti haidnya). Dari pendekatan tersebut, perlu penafsiran ulang bahwa wanita yang dicerai suaminya kemudian tidak haid, hendaknya menunggu sampai tiga bulan. Hal tersebut berbeda dengan pandangan fukaha selama ini, yang hanya membatasi kalimat "wa al-lâi lam yahidhna" (dan wanita yang tidak haid) tersebut pada iddah wanita yang masih kecil, yang belum pernah haid sama sekali.

Ketiga, urutan ketiga dari ayat ini adalah "wa ulât al-ahmâl ajaluhunna an yadha'na hamlahun" (dan wanita hamil hendaknya menunggu masa iddah mereka hingga melahirkan kandungannya). Hikmah yang terkandung dari urutan tersebut adalah dari pendekatan medis diketahui bahwa diantara sebab wanita tidak haid $^{58}$ adalah adanya kehamilan, dan kehamilan biasanya dapat diketahui dengan pasti ketika usia janin memasuki umur tiga bulan. ${ }^{99}$ Ketika seorang wanita yang dicerai dipastikan hamil, maka iddahnya dihitung sampai melahirkan.

Selain itu, kalimat yang digunakan tentang iddah yang habis dengan melahirkan adalah "an yadha'na hamlahun" (melahirkan kandungan) dan tidak menggunakan "yalidna" (melahirkan). Dari pendekatan medis diketahui, bahwa kehamilan terjadi semenjak bertemunya sel sperma dengan sel telur dan berlangsung hingga melahirkan. Kehilangan kehamilan bisa terjadi kapanpun selama masa kehamilan, baik karena abortus, kelahiran prematur, atau kelahiran cukup umur. Berdasarkan hal tersebut iddah wanita yang mengalami abortus kompletus adalah sama dengan iddah wanita hamil yang melahirkan.

\footnotetext{
${ }^{57}$ Wanita yang mengalami amenorea primer, diharapkan memeriksakan dirinya ketika usia 16 - I8 tahun tidak mengalami haid, karena terdapat kemungkinan adanya kelainan organ reproduksinya, misalnya karena tiadanya lobang pada himen, sehingga menghalangi keluarnya darah haid, atau karena kelainan kromoson bahwa ia tampil cantik tetapi memiliki gen laki-laki.

58 Baik pada amenorea primer maupun sekunder.

59 Meskipun saat ini terdapat alat medis yang bisa mengetahui adanya kehamilan sejak dini, tetapi secara manual, biasanya seorang ibu merasa yakin hamil setelah tiga-empat bulan.
} 
Dari penjelasan di atas diketahui bahwa iddah wanita perimenopause dan wanita yang pernah haid, namun terhenti haidnya bukan karena kehamilan, masa iddahnya adalah tiga bulan. Hal tersebut berbeda dengan pandangan fukaha selama ini, yang mayoritas berpendapat untuk menunggu 9 bulan (iddah wanita hamil) atau menunggu satu tahun (gabungan antara iddah wanita hamil, 9 bulan, dengan iddah wanita yang tidak haid, 3 bulan), atau bahkan menunggu sampai haid lagi.

Penjelasan tersebut menandakan bahwa ayat al-Qur'an 65:4 tersebut menyempurnakan masa iddah wanita yang belum tercakup dalam ayat al-Qur'an, 2:228 dan ayat al-Qur'an, 2:231. Ayat al-Qur'an 65:4 mencakup iddah wanita menopause, perimenopause, post menopause, amenorea primer, amenorea sekunder, wanita istihadhah, dan wanita hamil dengan kelahiran atau abortus kompletus.

\section{Penutup}

Berdasarkan pendekatan medis diektahui bahwasanya menopause adalah Menopause ialah haid terakhir, atau saat terjadinya haid terakhir. Diagnosis menopause dibuat setelah terdapat amenorea sekurang-kurangnya satu tahun (12 bulan). Amenorea ialah keadaan tidak adanya haid untuk sedikitnya 3 bulan berturut-turut. Amenorea dibedakan menjadi dua jenis: 1) Amenorea primer, yaitu tidak terjadinya haid. Amenorea primer apabila seseorang seorang wanita berumur 18 tahun ke atas tidak pernah haid. 2) Amenorea sekunder, yaitu tidak terjadinya haid yang diselingi dengan perdarahan haid sesekali pada wanita yang mengalami amenorea. Kehamilan tejadi dengan konsepsi (pembuahan) dan berakhir dengan permulaan persalinan. Persalinan ialah proses pengeluaran bayi dan uri dari badan ibu. Lamanya kehamilan yang normal adalah 280 hari atau 40 minggu dihitung dari hari pertama haid yang terakhir. Kadang-kadang kehamilan berakhir sebelum waktunya dan ada kalanya melebihi waktu yang normal. Berakhirnya kehamilan sebelum anak dapat hidup di dunia disebut abortus. 
Dengan pendekatan medis diketahui beberapa hal, di antaranya: Pertama, penyebutan "in irtabtum" (jika kalian ragu) bagi iddah wanita menopause, bahwa sebelum menopause biasanya wanita mengalami haid yang tidak teratur, dan dalam perspektif medis, seorang wanita dikatakan menopause apabila sudah tidak haid selama satu tahun. Kedua, penyebutan wanita belum haid sebelum hamil, karena secara medis, wanita belum haid (amenorea) ada dua; amenorea primer dikarenakan belum haid sama sekali dan amenorea sekunder dikarenakan kehamilan atau sebab lain. Ketiga, penyebutan iddah wanita hamil dengan kalimat "an yadha'na hamlahunna" bukan dengan kalimat "an yalidna", bahwa kehamilan telah terjadi ketika ovum bertemu sperma, maka ketika kehamilan itu tiada, baik karena keguguran atau melahirkan maka masa iddahnya berakhir.

Berdasarkan hal tersebut, maka penulis berpendapat bahwa: 1) iddah wanita perimenopause sama dengan wanita menopause yaitu tiga bulan. 2) iddah wanita yang belum haid sama sekali (amenorea primer), yang tidak hamil, adalah tiga bulan. 3) iddah wanita muda yang pernah haid lalu tidak haid (amenorea sekunder), bukan karena kehamilan, adalah tiga bulan. 3) iddah wanita mustahâdhah adalah tiga bulan. 4) iddah wanita hamil adalah sampai kehilangan kehamilannya, baik karena keguguran atau melhirkan bayi yang sempurna.

\section{Daftar Pustaka}

Qurthubi (al-). al-Jâmi' li Ahkâm al-Qur'ân. Juz 18. Beirut: Dâr alKutub al-Ilmiyyah, 1993.

Shabuni (al-), Muhammad Ali. Tafsîr Âyât al-Ahkâm. Beirut: Dâr alKutub al-'Ilmiyyah, t.t..

Zuhaili (al-), Wahbah. al-Tafsîr al-Munîr. Juz 28. Beirut: Dâr al-Fikr, 1991.

Glasier, Anna dan Ailsa Gebbie. Keluarga Berencana dan Kesehatan Reproduksi. Jakarta: EGC, 2006. 
Helim, Abdul. "Membaca Kembali Doktrin Iddah dalam Perspektif Ushûl al-Fiqh", Karsa, Volume 20, Nomor 2. Desember Tahun 2012.

Hendrik. Problema Haid Tinjauan Syariat Islam dan Medis. Solo: Tiga Serangkai, 2006.

Indar. "Iddah dalam Keadilan Gender", Yinyang, Volume 5, Nomor 1. Januari-Juni 2010.

Jamhuri dan Izzudin Juliara. "Penggabungan Iddah Wanita Hamil dan Kematian Suami (Analisis terhadap Pendapat Mazhab Syafi'i)", Samarah: Jurnal Hukum Keluarga dan Hukum Islam, Volume 1, Nomor 1. Tahun 2017.

Lailatul Musyafa'ah, Nur. "Rekonstruksi Fiqh Pendarahan Pervaginam dengan Pendekatan Medis", Islamica, Volume 8, Nomor 1. September 2013.

Lailatul Musyafa'ah, Nur. "Relevansi antara Medis dan Fikih tentang Perdarahan pervaginam", Jurnal Studi Gender Indonesia, Volume 05, Nomor 02. November 2016.

Muslimin, Ahmad. "Iddah dan Ihdad Wanita Modern", Mahkamah. Volume 2, Nomor 2. Desember 2017.

Nuha, Ulin. Analisis Pendapat Mazhab Hanafi tentang Iddah bagi Wanita yang belum Haid. Skripsi, Semarang: Uinversitas Islam Negeri, 2016.

Nurnazli. "Relevansi Penerapan Iddah di Era Teknologi Modern", Ijtimaiyya: Jurnal Pengembangan Masyarakat Islam, Volume 10, Nomor 1. 2017.

Sastrawinata, Sulaiman. "Wanita dalam Berbagai Masa Kehidupan", Abdul Bari Saifuddin (et. Al.), Ilmu Kandungan. Jakarta: Yayasan Bina Pustaka Sarwono Prawirohardjo, 2007.

Shalih, Su'ad Ibrahim. Adhwâa' 'alâ Nidzâm al-Usrah fi al-Islâm. Zaitun: Dâr al-Diya', 1996.

Simanjuntak, Pandapotan. "Gangguan Haid dan Siklusnya", Ilmu Kandungan. Jakarta: Yayasan Bina Pustaka Sarwono Prawirohardjo, 2007. 
Susilo, Edi. "Iddah dan Ihdad Wanita Karir", al-Hukama: The Indonesian Journal of Islamic Family Law. Volume 06, Nomor 02. Desember 2016.

Wahyudi, Muhammad Isna. Figh Iddah Klasik dan Kontemporer. Yogyakarta: LkeS, 2009.

Wijayanti, Daru. Fakta Penting Seputar Kesehatan Reproduksi Wanita. Yogyakarta: Bookmarks, 2009.

Undang-undang Perkawinan di Indonesia dilengkapi Kompilasi Hukum Islam. Surabaya: Arkola, tt..

Tim Bagian Obstetri dan Ginekologi Fakultas Kedoketran Universitas Padjajaran. Obstetri Fisiologi. Bandung: Universitas Padjajaran, 1983.

Tim Bagian Obstetri dan Ginekologi Fakultas Kedoketran Universitas Padjajaran. Obstetri Patologi. Bandung: Universitas Padjajaran, 1984.

“Gangguan pada masa Bayi, Kanak-kanak, Pubertas, Klimakterium, dan Senium". Ilmu Kandungan. Jakarta: Yayasan Bina Pustaka, 2007. 